\title{
Gold and penicillamine: A proposed mode of action in rheumatoid arthritis, based on synovial fluid analysis
}

\author{
M. H. PRITCHARD AND G. NUKI \\ From the Departments of Medicine and Rheumatology, Rheumatology Research Laboratory, Welsh National \\ School of Medicine, Llandough Hospital, Penarth
}

SUMMARY Although in common use, there is still controversy as to the way in which gold and penicillamine act in rheumatoid arthritis (RA).

In this study, synovial fluids from 4 groups of patients have been compared: (1) RA patients on gold/penicillamine, (2) RA patients on non-steriodal anti-inflammatory drugs (NSAID) only, (3) osteoarthritis patients, and (4) patients with sero-negative arthropathies. The parameters measured were differential agglutination titre (DAT), total haemolytic complement (CH50), total protein, total white cell count, and immunoglobulins. RA patients on gold/penicillamine have lower synovial DAT levels and higher CH50 levels than RA patients on NSAID only, and total and cryoprecipitable IgM levels very close to those found in the sero-negative joint fluids. The non-specific inflammatory parameters, ie, white cell count and total protein are unchanged after gold/penicillamine therapy.

In a second study, the serum DATs of patients in total remission after gold/penicillamine were compared with similar patients on NSAID only. The DAT falls significantly in the former group $(\mathrm{P}<0.001)$, but not in the latter suggesting that fall in DAT is a consequence of therapy rather than remission.

The parameters altered by gold/penicillamine in the synovial fluid are those that distinguish RA from non-rheumatoid arthropathies suggesting the drug's primary effect is to render the disease sero-negative. The results support the hypothesis that both drugs have a common mode of action based on their active thiol groups, and that the fall in DAT is due to the redustion of the antigenicity of the IgG complexes.

Although gold salts (Empire Rheumatism Council, $1960 ; 1961)$ and more recently, D-pencillamine (Golding et al., 1970; Multicentre Trial Group, 1973), have been shown to have a beneficial effect in the treatment of rheumatoid arthritis, there is still considerable controversy as to the mechanism of their anti-rheumatic action.

It is also uncertain whether it is the gold itself or the organic residue which carries the anti-rheumatic effect. Animal experiments, where successful, have suggested that the gold was the more important part of the molecule (Preston et al., 1942) but Jaffe (1977) has pointed out that the only gold salts that in practice had anti-rheumatic activity were those containing a sulphydryl (SH) group. Of these, only

Accepted for publication January 20, 1978

Correspondence to Dr M. H. Pritchard, Department of Rheumatology, University Hospital of Wales, Cardiff. aurothiomalate (Myocrisin) and aurothioglucose (Solganol) have stood the test of time.

Penicillamine was originally proposed for the treatment of rheumatoid arthritis because of its ability to dissociate macroglobulins (Deutch and Morton, 1957) .However, Jaffe (1962) demonstrated that dissociation of rheumatoid factor only occurred following injection of penicillamine directly into the joints of patients with RA and even then the effect was temporary. He also showed that prolonged administration of penicillamine could bring about a fall in rheumatoid factor (Jaffe, 1963) but later concluded (Jaffe, 1965) that this was unlikely to be due to simple splitting of the macroglobulins as it could not account for the time lapse between initiation of treatment and clinical effect.

In a recent clinical trial (Huskisson et al., 1977) clinical improvement and fall in rheumatoid factor were noted in patients on both gold and 
penicillamine; no difference between the 2 drugs was observed in either clinical or biochemical parameters.

In addition to both being slowly effective in the treatment of RA, the 2 drugs have many similarities in their side effects, chemical structure and biochemical actions (Jellum and Munthe, 1977). In this paper we have studied some changes in synovial fluid in a large number of patients with rheumatoid arthritis treated with these 2 drugs, and propose a mode of action based on the results.

\section{Materials and methods}

\section{PATIENTS}

Synovial fluid was obtained from the knee joints of 162 patients attending routine hospital out-patient clinics, using normal aseptic techniques. The patients were classified under 4 clinical headings. (1) Sixtyone patients with classical rheumatoid arthritis (ARA criteria, Ropes et al., 1959) taking nonsteroidal anti-inflammatory drugs (NSAID) only. (2) Thirty-nine patients with classical RA receiving gold or penicillamine. (3) Twenty-four patients with osteoarthritis. (4) Thirty-eight patients with seronegative arthropathies. The sero-negative group consisted of ankylosing spondylitis (2), amyloid arthropathy (5), polymyalgia rheumatica (3), psoriatic arthropathy (9), Reiter's disease (6), sarcoidosis (4), and juvenile chronic arthritis (Still's disease; 9).

The selection of patients on gold or penicillamine for these studies was necessarily limited to those patients with a significant joint effusion. We therefore defined this group of patients as 'partial responders', and even though the clinical response to drug therapy varied considerably, for purposes of analysis the group is treated in this paper as being homogenous. All patients had been on treatment for at least 3 months.

A second group of patients with classical rheumatoid arthritis was studied, in whom tests for rheumatoid factor were correlated with treatment and remission. These patients were selected on the basis of both clinical response and therapy, and consisted of (1) patients in 'complete' remission following gold or penicillamine therapy; (2) patients who had either made no response whatever to gold or penicillamine, or who had relapsed following an initial improvement; and (3) patients who had gone into 'complete' remission while taking NSAID with or without hydroxychloroquine. Complete remission for the first and last groups was defined as (1) less than 15 min morning stiffness for at least the last 6 months, (2) minimal or no joint symptoms, requiring occasional or low dose analgesics only, and (3) erythrocyte sedimentation rate (Westergren) than $20 \mathrm{~mm} / \mathrm{h}$. All patients had previously hag active seropositive polyarthritis.

\section{LABORATORY METHODS}

Ten to $15 \mathrm{ml}$ of synovial fluid were allowed to stand after aspiration for about $30 \mathrm{~min}$ at room tempe ature, and 150 units of hyaluronidase (hyalase

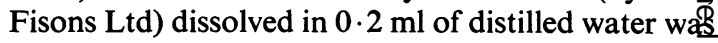
added. After standing in a waterbath at $37^{\circ} \mathrm{C}$ fof $10 \mathrm{~min}$, the fluid was centrifuged for $5 \mathrm{~min}$ at $500 \mathrm{~g}$ and the sediment discarded. Ten $\mathrm{ml}$ of the clear supernatant was then kept in the refrigerator at $4^{\circ} \mathrm{C}$ for 72 hours, to allow cryoprecipitation $\mathscr{P}^{\mathbb{P}}$ immune complexes (Marcus and Townes, 1971导 The remainder of the fluid was used for estimation of the protein content, the differential agglutination titre (DAT), total haemolytic complement activify (CH50) and immunoglobulin concentrations (Igeo and $\operatorname{IgM}$ ).

The protein concentration was calculated by measuring the extinction at $280 \mathrm{~nm}$ on a Unicar SP 500 ultra-violet spectrophotometer. It was found that the error due to nucleic acids, which have at extinction peak at $260 \mathrm{~nm}$, was less than $2 \%$ an was ignored.

Serum and synovial fluid DAT levels measured using sensitised sheep red cells (Rose \& al., 1948).

$\mathrm{CH} 50$ in serum and synovial fluid was measuree using a slight modification of the method describe by Kabat and Mayer (Mayer, 1961), reducing a volumes by a factor of $2 \cdot 5$. A standard curve w\$ constructed by plotting percentage haemolysis against serial dilutions of guinea pig complement (Gibco), using sheep red cells prepared in the laboratory and stored in Alsever's medium. The cells were sensitised by incubation with horse hac molytic antiserum (Wellcome Laboratories). Twō different dilutions of the sample under test were incubated with the cells for 1 hour at $37^{\circ} \mathrm{C}$. Haemo lysis was measured on a Unicam SP 600 spectro photometer at $541 \mathrm{~nm}$, and the $\mathrm{CH} 50$ calculated from the standard graph in units $/ \mathrm{ml}$. Only the central portion of the S-shaped standard curve, ie, that between $25 \%$ and $75 \%$ haemolysis, was used for this. calculation. (Mean differences between duplicates falling on this portion of the curve (20 samples) was 1.1 units, SD 0.84 units.) The method proved to be simple and reproducable allowing up to a dozew samples to be processed simultaneously.

Immunoglobulins were measured by radiad immunodiffusion against commercial antisera (Wel come Laboratories) on plates containing $0.6 \%$ Ionagar (Oxoid) made up in the laboratory in barbid tone acetate buffer $p \mathrm{H} 8 \cdot 2$ ionic strength $0 \cdot 05$. 
The cryoprecipitates obtained after standing the synovial fluid at $4^{\circ} \mathrm{C}$ for 72 hours were centrifuged at $4^{\circ} \mathrm{C}$ for $5 \mathrm{~min}$ at $500 \mathrm{~g}$. The precipitate was then dispersed in phosphate buffer (ionic strength $0 \cdot 1$, $p \mathrm{H} \mathrm{7.4)}$ at $37^{\circ} \mathrm{C}$. IgG and IgM were measured by radial immunodiffusion as described above.

In order to distinguish between cryoprecipitable immunoglobulins and other cryoproteins a further step was carried out. The dissolved cryoprecipitate was dialysed at $4^{\circ} \mathrm{C}$ for 72 hours against $0.02 \mathrm{~mol} / 1$ veronal buffer, $p \mathrm{H} 8.6$. This resulted in a fine white flocculant precipitate that redissolved instantly in phosphate buffer at room temperature. Analysis of the first and second stage cryoprecipitates showed that only immunoglobulins and a trace of albumen were detectable after the second stage, while other cryoproteins such as fibrinogen and DNA, which were present in the first cryoprecipitate, were absent.

\section{Results}

Table 1 shows the synovial fluid (SF) CH50 values for each of the 4 groups, without adjustment for serum complement levels. It can be seen that the group of patients with RA treated with gold or penicillamine have a significantly higher mean $\mathrm{CH} 50$ level $(\mathrm{P}<0.01)$ than those treated with antiinflammatory drugs alone, and the value is in fact slightly closer to that of the sero-negative arthropathies. If the figures for the gold/penicillamine group are analysed for the 2 drugs separately there is no difference between them.

Pekin and Zvaifler (1964) and Hedberg (1967) have shown that synovial $\mathrm{CH} 50$ is influenced by serum CH50. Corresponding serum complement activity was available in about half the patients in whom synovial fluid was analysed, and Table 2 shows the SF CH50 in 2 groups of patients before and after correcting for serum CH50. Correction was carried out by proportional reduction of SF CH50 after scaling down the corresponding serum $\mathrm{CH} 50$ to a value of 30 units $/ \mathrm{ml}$.

Table 1 Synovial CH50 levels (units/ml, mean $\pm S D$ ) in 4 groups of patients

\begin{tabular}{lll}
\hline & No. & CH5O \\
\hline Osteoarthritis & 24 & $12 \cdot 6 \pm 2 \cdot 6$ \\
RA (NSAID) & 61 & $7 \cdot 2 \pm 5 \cdot 0$ \\
Sero -ve arthropathies & 38 & $18 \cdot 7 \pm 5 \cdot 7$ \\
RA gold/pen & 39 & $13 \cdot 3 \pm 7 \cdot 1$ \\
(gold) & 20 & $14 \cdot 9 \pm 8 \cdot 4$ \\
(pen) & 19 & $12 \cdot 3 \pm 6 \cdot 2$ \\
\hline
\end{tabular}

All differences between means are significant $(P<0.01)$, except $R A$ gold/pen $v$ OA (NS) and RA (gold) $v$ RA (pen) (NS).

RA=rheumatoid arthritis. NSAID $=$ non-steroidal anti-inflammatory drugs. Sero-ve =sero-negative. Pen = penicillamine. $\mathrm{OA}=$ osteoarthritis.
Table 2 Synovial CH50 levels (units/ml, mean $\pm S D$ ) before and after scaling the corresponding serum CH5O levels to 30 units $/ \mathrm{ml}$

\begin{tabular}{lcc}
\hline Group & Original CH5O & Corrected CH5O \\
\hline Gold/penicillamine & $13 \cdot 1 \pm 7 \cdot 1$ & $9 \cdot 4 \pm 3 \cdot 3$ \\
Sero-negative & $18 \cdot 7 \pm 5 \cdot 7$ & $13 \cdot 1 \pm 3 \cdot 0$ \\
Ratio of means & $0 \cdot 70$ & $0 \cdot 71$ \\
\hline
\end{tabular}

Although adjusting the SF CH50 to a constant serum value reduces the mean values in each case, they remain proportionately the same. The standard deviation is however, substantially reduced.

DAT values were obtained for all RA synovial fluids, and the results are shown in Fig. 1. This

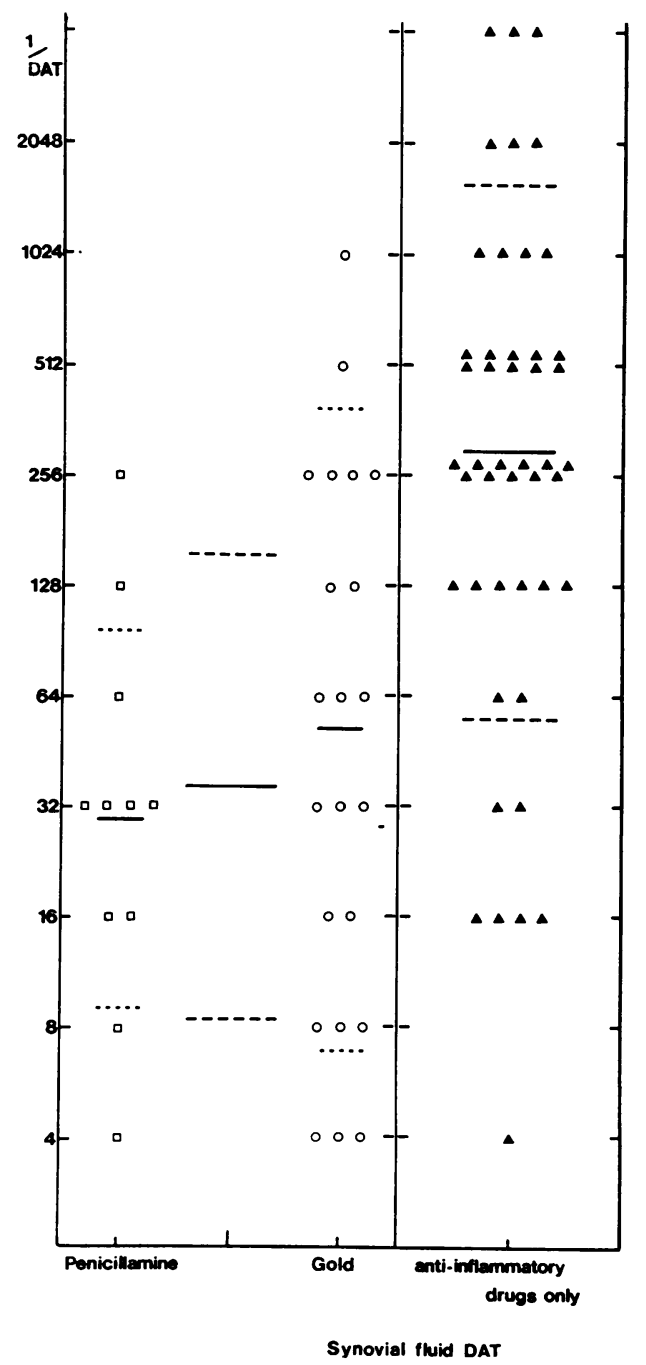

Fig. 1 Synovial $D A T$ values (mean $\pm S D$ ) for patients with RA (I) on gold/penicillamine and (2) on NSAID. 
shows that patients being treated with gold or penicillamine have significantly lower DAT levels than those taking NSAID only, $(P<0 \cdot 01)$. The figure also shows that when the gold and penicillamine results are analysed separately, there are no significant differences between them.

Figure 2 shows the correlation between SF and serum DAT values in 50 patients with RA. The correlation is fairly strong $\mathrm{r}=0.71, \mathrm{P}<0.01$, and confirms the results of Huskisson et al. (1971).

The wide range of clinical responses in this group of 'partial responders' made them unsuitable subjects for attempting to ascertain whether falls in titre of rheumatoid factor are simply a consequence of disease remission or the result of some specific effect of gold or penicillamine. In order to answer this question the changes in serum DAT following drug therapy were examined in the previously defined second group of patients with classical RA. The results are shown in Fig. 3. There is a mean fall in serum DAT of 3.7 tube dilutions $(P<0.001)$ in those patients going into 'complete' remission following administration of gold or peni-e cillamine. In comparison there is a mean fall in DAT of less than 0.5 tube dilutions in the NSAID treated? patients in a similar 'complete' remission. Patientse who have failed to respond to gold or penicillamine, or who have relapsed to their original clinical state $\vec{\nabla}$ also show no change in their mean DAT. The fall in serum DAT appears to be related to a specifics action of successful gold or penicillamine therapy $\overrightarrow{0}$ rather than remission per se.

Figure 4 shows the correlation between $\mathrm{SF}$ CH50w (adjusted to a constant serum CH50 level of 30 units $\mathrm{ml}$ ) and SF DAT. The correlation is significanto but relatively weak $(\mathrm{r}=-0.55, \mathrm{P}<0.01)$.

Figure 5 illustrates synovial fluid protein andb white cell count measurements, together with thet concentrations of total and cryoprecipitable IgG and IgM. The statistical analysis of the results is

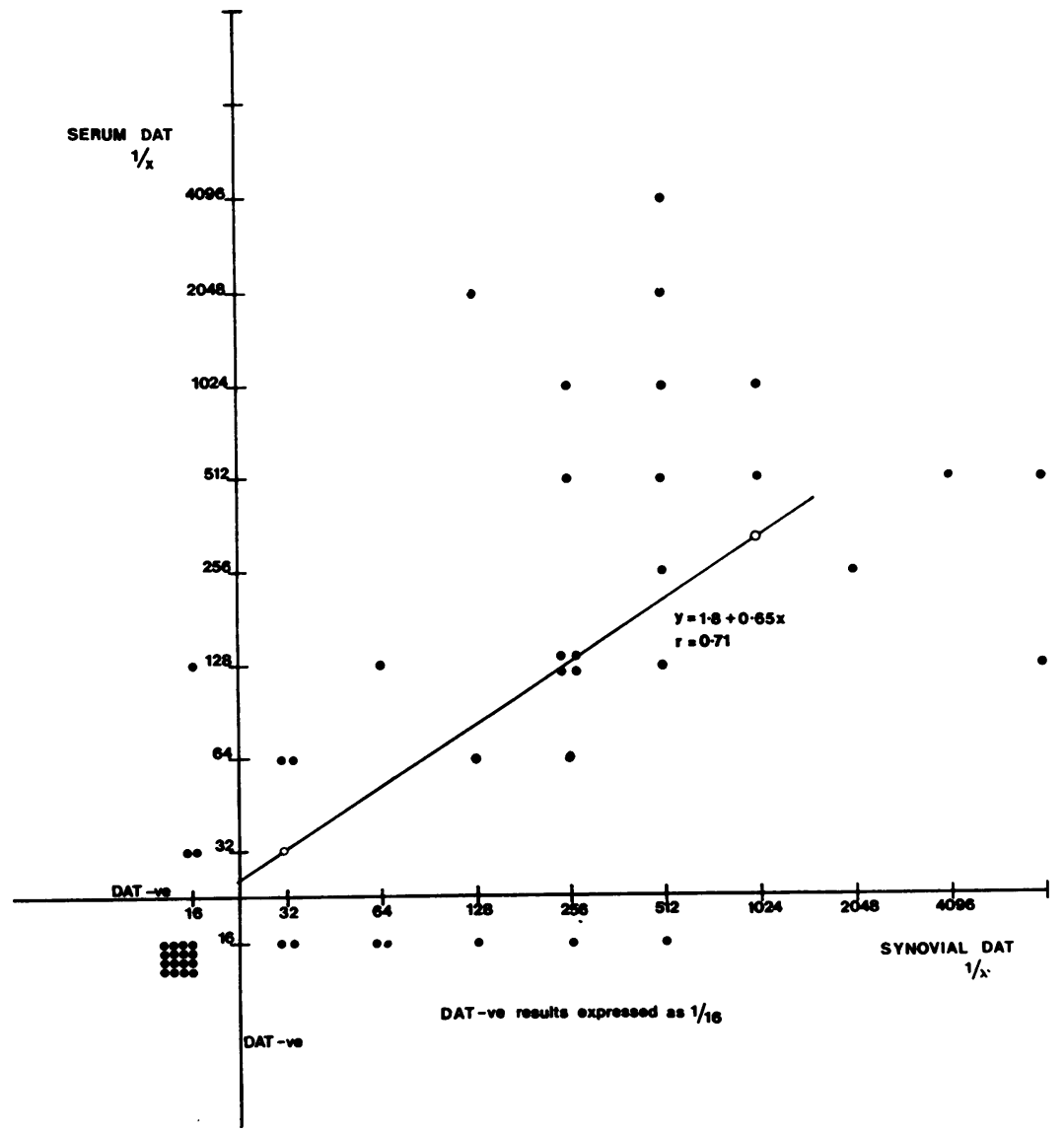

Fig. 2 Correlation between serum DAT and SF DAT in patients with $R A$. 
shown in Table 3. The cryoprecipitate values given are those obtained from single-stage cryoprecipitation.

Having shown that the immunoglobulins could be reprecipitated in the cold from phosphate buffer in the absence of other cryoproteins, the concentrations of IgG (45 samples) and IgM (34 samples) in the final cryoprecipitate were plotted against the corresponding values in the first-stage cryoprecipitate. The results (Figs. 6 and 7) show that there is a strong correlation between the concentrations in the two precipitates (IgG: $\mathrm{r}=\mathbf{0} \cdot \mathbf{8 2}, \mathrm{P}<\mathbf{0 . 0 0 1}$, IgM $r=0.86, P<0.001)$. Approximately $35 \%$ of the IgM and $60 \%$ of the IgG is lost in reprecipitation. The reason for this is not certain but may be related to the dynamic equilibrium that can be demonstrated in synovial fluid between free and complexed IgG. For example if a cryoprecipitate is removed from the synovial fluid, and the supernatant returned to the refrigerator, a further cryoprecipitate will form. By
REMISSION

(Gold/penillamine)
FAILED/AELAPSED

(Gold/penicillamine)
REMISSION

(spomtancous)

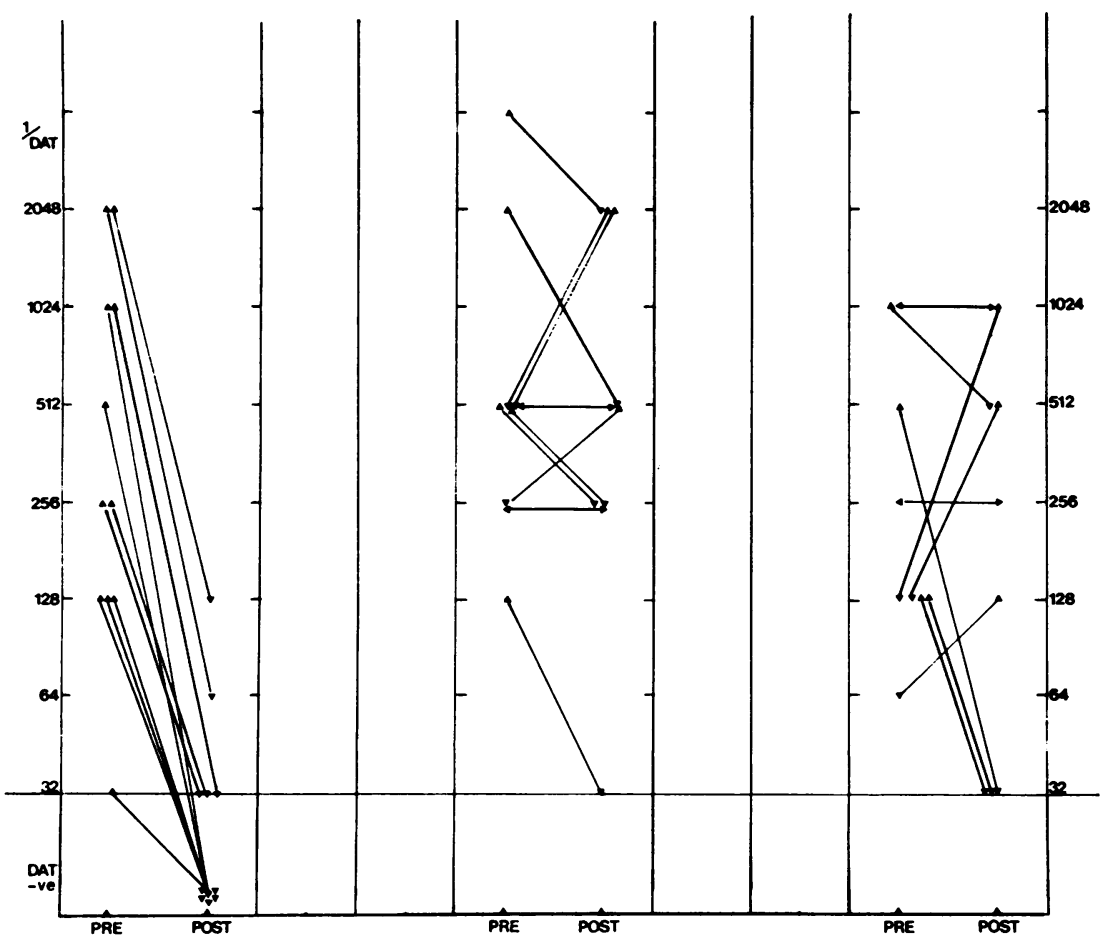

Fig. 3 Changes in serum DAT in 3 groups of patients following drug therapy, (1) remission on gold/penicillamine, (2) failed/relapsed on gold/penicillamine, (3) remission on NSAID only.

Table 3 Statistical analysis of synovial fluid constituents (Fig. 5)

\begin{tabular}{|c|c|c|c|c|c|c|}
\hline & \multicolumn{2}{|c|}{$\lg G(\mathrm{~g} / 100 \mathrm{ml})$} & \multicolumn{2}{|c|}{$\lg M(\mathrm{~g} / 100 \mathrm{ml})$} & \multirow{2}{*}{$\begin{array}{l}\text { Leucocytes } \\
/ \mathrm{mm}^{3}\end{array}$} & \multirow{2}{*}{$\begin{array}{l}\text { Total protein } \\
9 / 100 \mathrm{ml}\end{array}$} \\
\hline & Total & Cryo & Total & Cryo & & \\
\hline $\begin{array}{l}\text { (1) RA (NSAID) } \\
\text { (2) RA Gold/pen } \\
\text { (3) Sero -ve arthritis }\end{array}$ & $\begin{array}{l}699 \pm 31 \\
632 \pm 30 \\
550 \pm 35\end{array}$ & $\begin{array}{l}60 \pm 13 \\
45 \pm 8 \cdot 4 \\
21 \pm 2 \cdot 9\end{array}$ & $\begin{array}{l}106 \pm 10 \\
81 \pm 6 \cdot 7 \\
78 \pm 6 \cdot 1\end{array}$ & $\begin{array}{l}6 \cdot 0 \pm 1 \cdot 2 \\
2 \cdot 6 \pm 0 \cdot 5 \\
2 \cdot 4 \pm 0 \cdot 7\end{array}$ & $\begin{array}{l}9400 \pm 950 \\
7200 \pm 1200 \\
10200 \pm 2000\end{array}$ & $\begin{array}{l}5 \cdot 6 \pm 0 \cdot 2 \\
5 \cdot 3 \pm 0 \cdot 2 \\
5 \cdot 8 \pm 0 \cdot 2\end{array}$ \\
\hline $\begin{array}{l}\text { Significance } \\
\mathbf{P}\end{array}$ & $\begin{array}{l}1 v 3 \\
<0.05\end{array}$ & $\begin{array}{lll}1 & v & 3 \\
2 & v & 3 \\
<0.05\end{array}$ & $\begin{array}{l}1 v 2 \\
1 v 2 \\
<0.05\end{array}$ & $\begin{array}{lll}1 & v & 2 \\
1 & v & 3 \\
<0 & .05\end{array}$ & NS & NS \\
\hline
\end{tabular}

All other comparisons 'not significant'. 
transferring the cryoprecipitate from synovial fluid to IgG-free phosphate buffer a new equilibrium is set up with less IgG available for complex formation. In view of the close correlation between the immunoglobulin concentrations found at each stage of cryoprecipitation, and taking into account the observation that IgM was not detected either in the osteoarthritic or in the majority of the sero-negative cryoprecipitates, we considered that the figures obtained in the first-stage cryoprecipitates were representative, and that further purification was unnecessary.

\section{Discussion}

The results obtained in this study show that treatment of rheumatoid arthritis with aurothiomalate or D-penicillamine is associated with substantial and similar changes in synovial fluid DAT, CH50, and cryoprecipitable IgM. As many of the clinical effects and side effects of the 2 drugs are also similar (Huskisson et al., 1977; Jaffe, 1977) it seems logical to look for a common mode of action.

Both aurothiomalate (Jessop and Currey, 1968) and penicillamine (Lyanage and Currey, 1972) show some specificity for rheumatoid disease (Jaffe, 1977) and are ineffective in experimental adjuvant arthritis in rats. Although several gold salts are reported to suppress the progressive chronic arthritis in rodents caused by repeated $\omega$ injection of pleuro-pneumonia like organisms (PPLO) (Preston et al., 1942), this property is shared by gold salts without anti-rheumatic activity in man, suggesting that it is unlikely to be음 important in its mode of action in clinical practice. $\frac{\bar{s}}{\frac{1}{2}}$ Similar reservations are applicable to the inter- $\stackrel{\otimes}{\propto}$ pretation of in vitro experiments which show inhibition of complement activity (gold-Schultz et al., 1974; penicillamine-Mellbye and Munthe, 1977); and this effect has at any rate never been $\vec{\omega}$ convincingly demonstrated in vivo. There are con-o flicting reports as to whether the drugs exert an immunosuppressive effect in man; but in guinea pigs they do not appear to exert a direct suppressive. effect on the immune response (gold-Persellin et al., 1967; penicillamine-Lyanage and Currey, 1973). Stabilisation of lysosomal membranes has been demonstrated for gold (Persellin and Ziff, 1966) but not for penicillamine (Chwalinska-Sadowska ando Baum, 1976). The latter authors found that penicillamine reduced polymorphonuclear leucocyte 3 (PMN) chemotaxis but this was not confirmed by Mowat (1977) who demonstrated that gold salts impaired PMN chemotaxis in a dose-related fashiog.

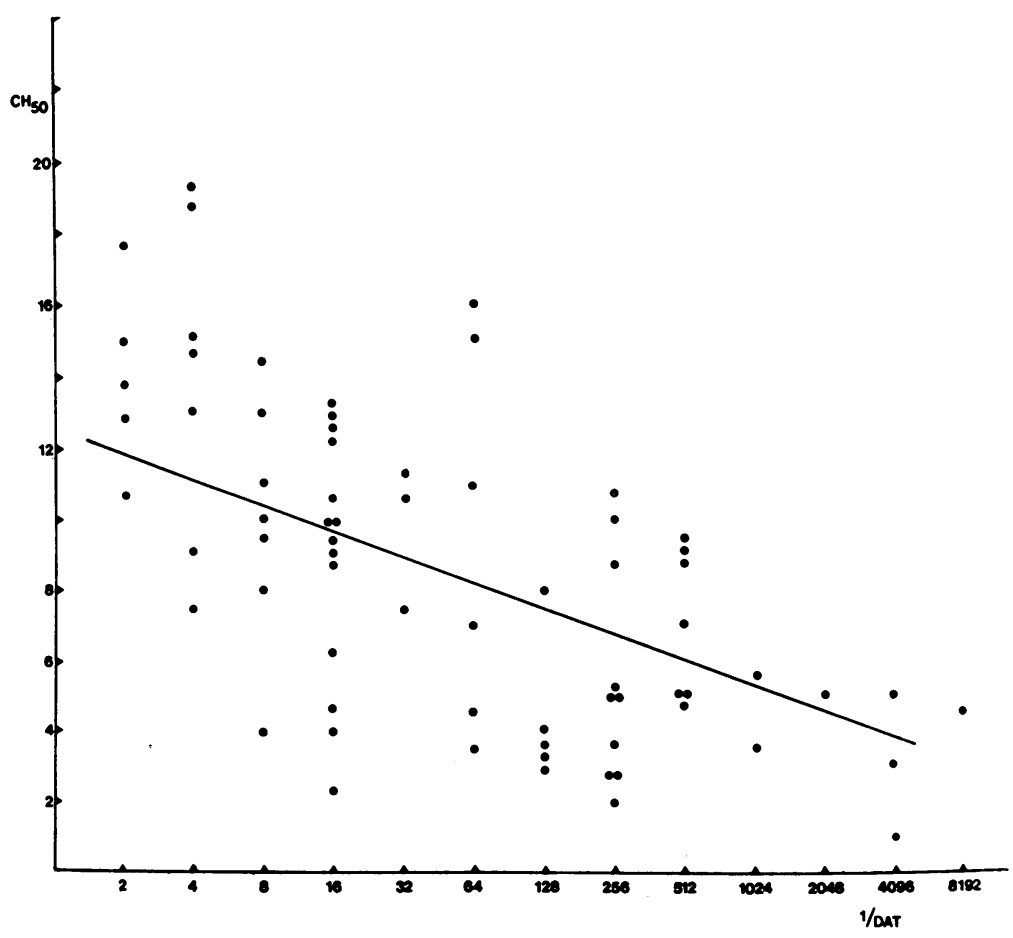

Fig. 4 Correlation between synovial $\mathrm{CH} 5 \mathrm{O}$ (corrected) and synovial DAT $(r=-0.55$, $P<0.01)$. 
The increased phagocytic activity of macrophages seen in skin windows in patients with RA is reduced following treatment with aurothiomalate (Jessop et al., 1973) but no information is available for penicillamine in this regard.

Neither drug has been shown to possess antiinflammatory activity in conventional animal models, but both drugs have some activity on infective agents (gold-Findlay, et al. 1940; penicillamine-Merryman et al., 1974). Finally, penicillamine has been shown to reduce the levels of circulating immune complexes in rheumatoid arthritis (Mohammed et al., 1976), and of physiologically occurring $\alpha$-antitrypsin IgA complexes, in which a disulphide bond is the linking factor (Wollheim et al., 1977).

We have shown that low levels of SF CH50 and high titres of DAT distinguish sero-positive from sero-negative arthritis and that gold and penicillamine treated patients form an intermediate group. On the other hand, the non discriminant parameters, such as total protein and white cell count, are the same in all 3 groups.
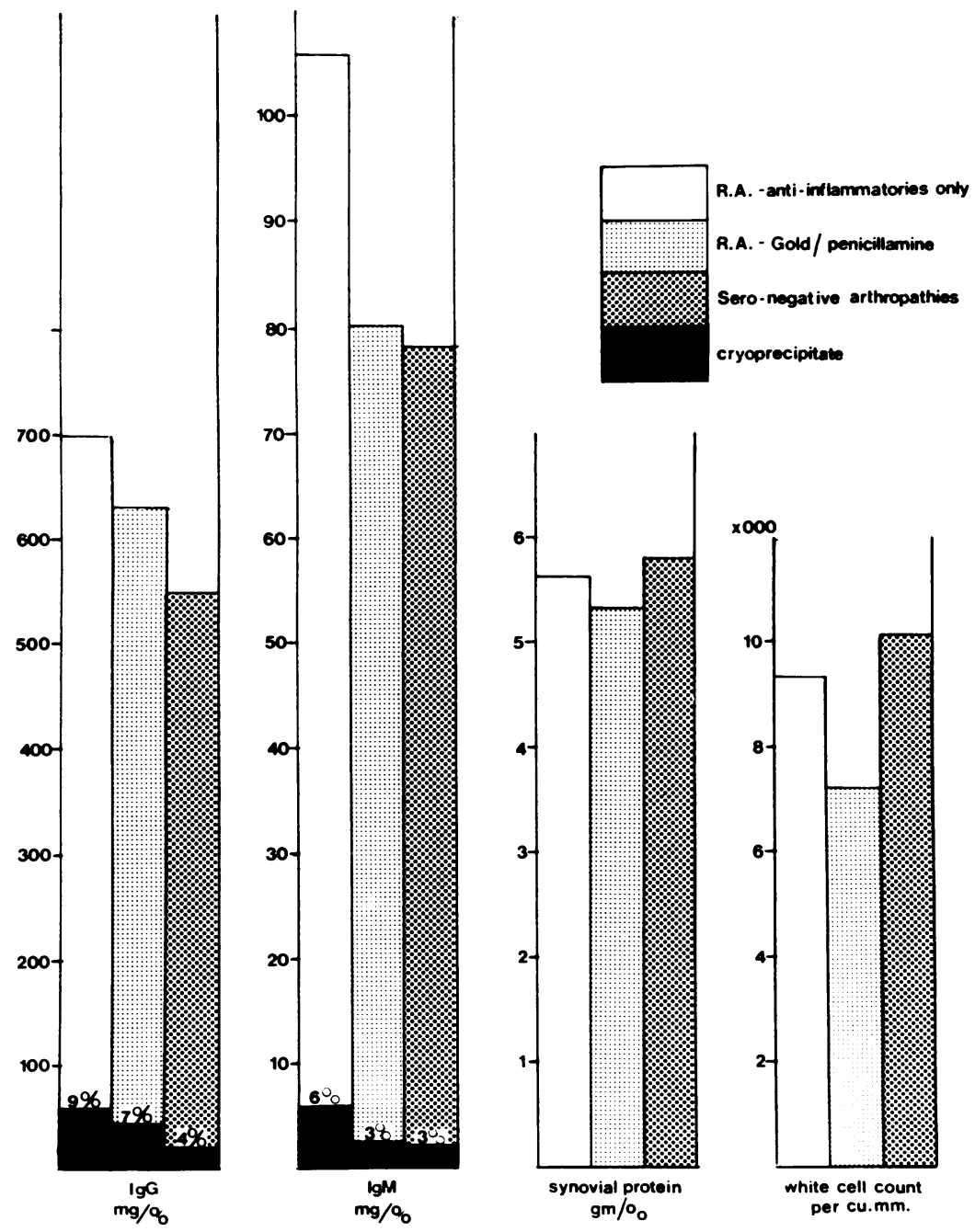

Fig. 5 Concentrations of synovial IgG, IgM, and protein, and total white cell count in 3 groups of patients (1) RA on NSAID, (2) RA on gold/penicillamine, (3) sero-negative arthropathies. Percentage values refer to $\%$ of total immunoglobulins that is cryoprecipitable.

Conversion: traditional to SI units- $\mathrm{IgG}, \mathrm{IgM}: 1 \mathrm{~g} / 100 \mathrm{ml}=10 \mathrm{~g} / \mathrm{l}$. Synovial protein: $1 \mathrm{~g} / 100 \mathrm{ml}=10 \mathrm{~g} / \mathrm{l}$. Leucocytes: $1 \times 10^{3} / \mathrm{mm}^{3}=1 \times 10^{9} / \mathrm{l}$. 


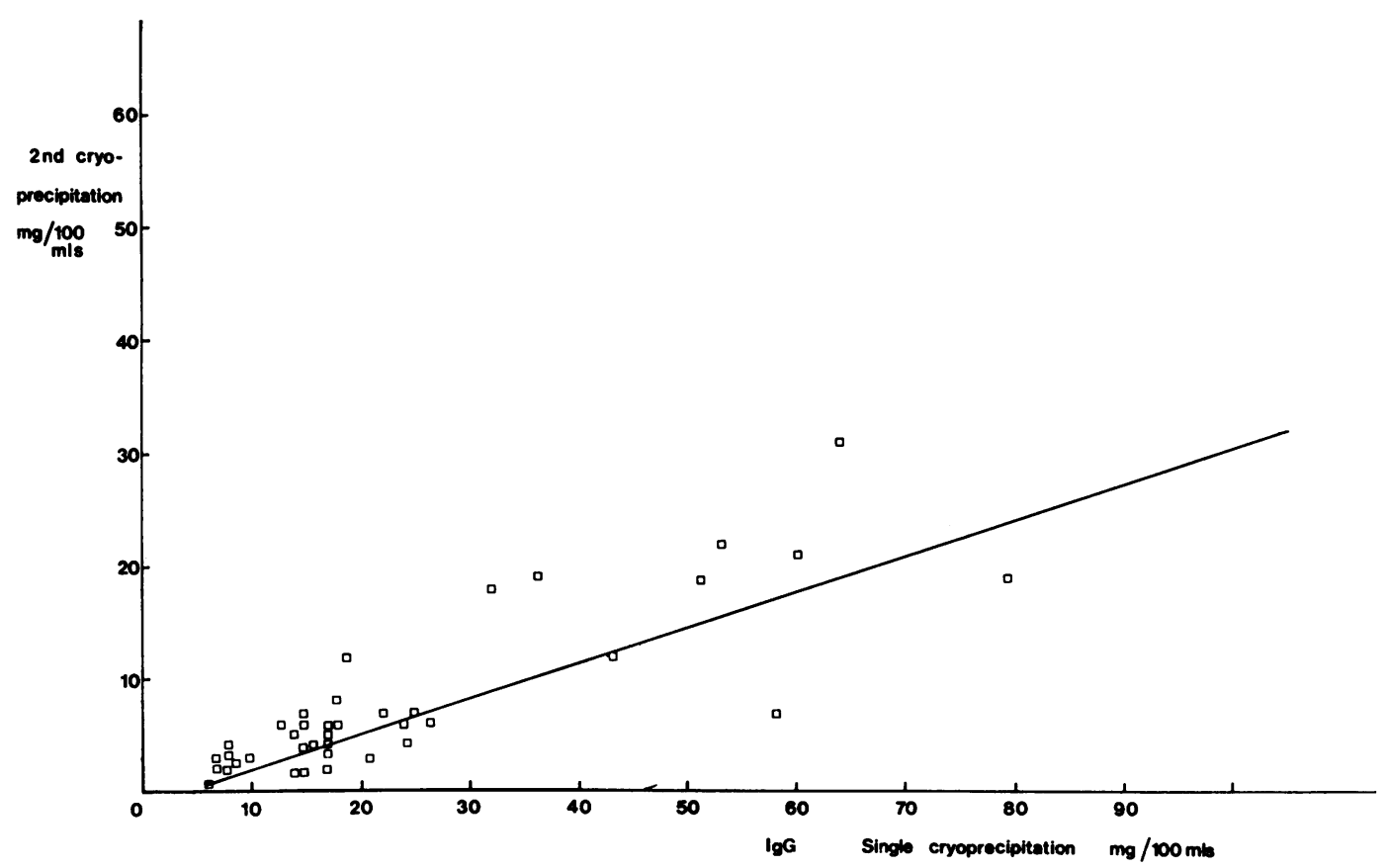

Fig. 6 Correlation between IgG concentration in the first cryoprecipitate against that in the second $(r=0 \cdot 82, P<0 \cdot 001)$.

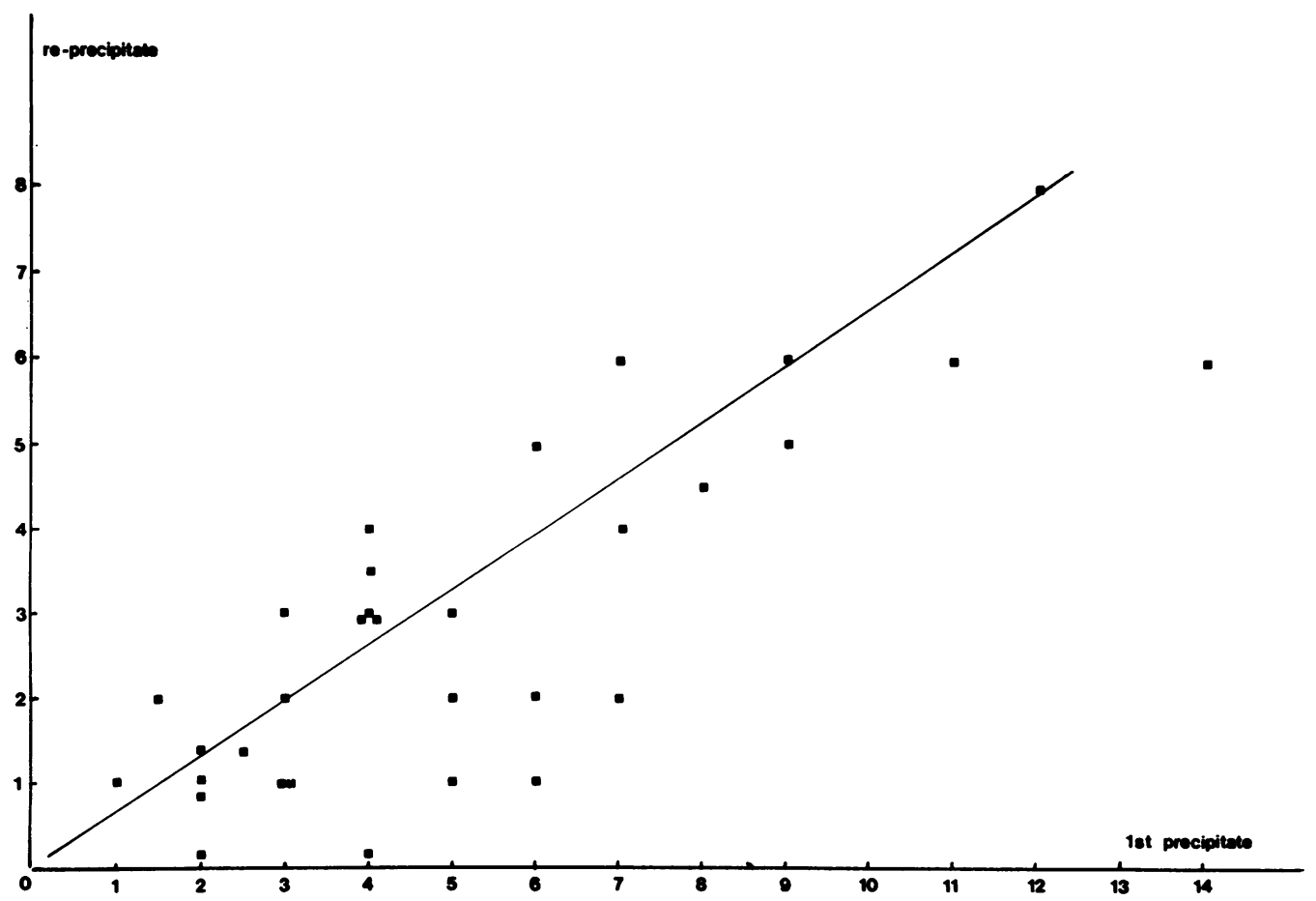

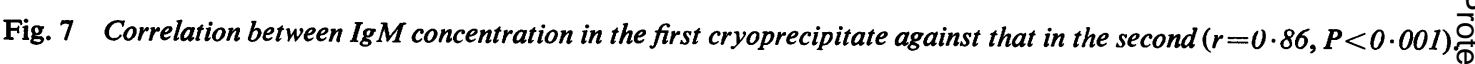


The total and cryoprecipitable IgM measurements are of particular interest, as the gold and penicillamine treated patients show similar results to the sero-negative patients. IgM in the cryoprecipitate is coprecipitated with complexed $\mathrm{IgG}$, and presumably has rheumatoid factor activity. Falls in cryoprecipitable IgM would therefore be expected to mirror changes in DAT.

It appears that gold and penicillamine, when effective, affect those parameters which best differentiate rheumatoid arthritis from sero-negative arthropathies. After successful treatment with either drug, sero-positive RA is converted to seronegative disease and the drugs could be said to be primarily 'antirheumatoid' rather than antiarthritic. This observation is in keeping with clinical findings. The majority of patients on these drugs go into sustained partial remission rather than into total remission, and appear to have a more benign form of arthritis.

It is of interest that while gold and penicillamine are ineffective in the HLA B27 associated arthropathies (Jaffe, 1977), many cases of juvenile chronic arthritis have been successfully treated with both drugs. We have found that over half of our patients with juvenile chronic arthritis (classified here as seronegative) have cryoprecipitable IgM in marked contrast to the vast majority of the other forms of sero-negative arthritis included in the group. A fall in cryoprecipitable IgM associated with a response to gold or penicillamine would be consistent with the above hypothesis but further detailed studies are necessary to ascertain the relationship between cryoprecipitable IgM and progressive joint disease.

It is unlikely that complement activity is being directly affected by either drug. Experiments on the effects of gold (Schultz et al., 1974) and penicillamine (Mellbye and Munthe, 1977) on complement components showed a reduction in complement activity in vitro but very little effect in vivo. The changes in synovial fluid DAT and the rise in CH50 are more likely to be related indirectly as the presence of rheumatoid factor is known to enhance complement consumption by immune complexes (Tesar and Schmid, 1970; Winchester et al., 1970). On the basis of this observation the reduction of rheumatoid factor concentration would therefore be expected to reduce the excessive complement consumption which occurs in rheumatoid synovial fluid.

The results of the small clinical survey of patients in total remission (Fig. 3) show that fall in DAT is more closely related to a response to gold/penicillamine treatment than to remission itself. Those patients in 'complete' remission on NSAID show only a slight fall in serum DAT, and are in sharp contrast with those patients who are in 'partial' remission on gold or penicillamine who show a considerable fall in DAT. In view of the demonstrated relationship between serum and SF DAT, the inference is that the fall in SF DAT is also a result of successful gold/penicillamine therapy.

The fall in rheumatoid factor could be a result of several different mechanisms. Firstly, inhibition of IgM synthesis at a cellular level; secondly, direct dissociation of macromolecular rheumatoid factors or alteration in their binding properties; thirdly, more efficient phagocytosis of the immune complexes by macrophages, and fourthly, a reduction of the stimulus to rheumatoid factor production.

Persellin et al. (1967) found no alteration in antibody responses in guinea pigs after gold therapy, when tested with standard antigenic stimuli and Lyanage and Currey (1972) found in guinea pigs no alteration in immune responses after pencillamine administration. It seems unlikely therefore that either drug is affecting IgM rheumatoid factor production by direct inhibition of antibody production.

The second possibility is also unlikely, as Jaffe (1962) has shown that it was extremely difficult to dissociate macroglobulins in vivo, and could only be done by injecting penicillamine directly into the joint. Even then, the result was transitory. $\mathrm{He}$ also pointed out that this mechanism failed to explain the delay between treatment and clinical response. An effect on IgM binding is ruled out by our finding that the fall in DAT is paralleled by a fall in the amount of total and cryoprecipitable $\operatorname{IgM}$ in the joint fluid. The fall is likely to be due to a reduction in the concentration of rheumatoid factor rather than differences in its ability to react with complexes.

Increased phagocytosis of complexes seems unlikely in view of the work of Jessop et al. (1973) who showed that macrophage phagocytosis fell after gold therapy in rheumatoid arthritis.

An effect on the stimulus to rheumatoid factor production has been proposed by Gerber (1975) and Evans (1975) on other grounds and is worth considering in more detail. The reaction between $\mathrm{IgG}$ complexes in rheumatoid synovial fluid and IgM rheumatoid factor was demonstrated by Hannestad (1967) and Winchester et al. (1970). On immunoelectrophoresis plates, Hannestad demonstrated a strong precipitin line between $\operatorname{IgM}$ rheumatoid factor and IgG obtained from rheumatoid joints. $\mathrm{He}$ found that there were similarities between this denatured form of $\operatorname{IgG}$ and that obtained by heating native IgG to $63^{\circ} \mathrm{C}$ for $30 \mathrm{~min}$, a reaction which was shown by Gerber to be due to sulphydryl-disulphide interchange resulting in steric rearrangement of the IgG molecule. Gerber also showed that copper was required to catalyse this reaction. 
The IgG complex in rheumatoid arthritis is the antigenic stimulus to $\operatorname{IgM}$ rheumatoid factor production, the antigenic site (or sites) being located in the Fc fragment. It has been proposed (Gaarder and Natvig, 1974) that the act of aggregation itself uncovers hidden antigenic sites on the molecule. However, this does not explain why the cryoprecipitable, complexed IgG in sero-negative arthropathies does not also stimulate IgM rheumatoid factor. This suggests that in rheumatoid arthritis a further reaction is required to expose the necessary antigenic sites.

Exposure of these sites requires rearrangement of the molecule, which in turn requires sulphydryldisulphide reactions to occur. Both gold thiomalate and penicillamine contain active thiol groups, and are structurally similar molecules in many respects. Jellum and Munthe (1977) showed that gold thiomalate rapidly dissociated when reacted with albumen, transferring the gold ion to the protein and leaving the thiomalate residue free. They also demonstrated that thiomalate, like penicillamine, was capable of both chelating metal ions, and reacting with protein-SS and protein-SH groups. Both drugs are therefore theoretically capable of interfering with the denaturation of IgG.

Although this has not been demonstrated in vivo, Gerber (1974) has shown that IgG did not denature at $63^{\circ} \mathrm{C}$ if certain molecules were present. Among these were aurothiomalate and penicillamine, and he suggested that they acted by inhibition of the copper catalysed aggregation reaction, possibly by chelating the copper itself.

Evans (1977) has shown that penicillamine will increase the serum SH levels in patients with rheumatoid arthritis. He proposed that it acted as a conformational catalyst, promoting the formation of 'correct' disulphide bonds during protein synthesis. Abnormal immunoglobulins are thereby slowly eliminated, and the stimulus to rheumatoid factor production falls.

Whether aurothiomalate and penicillamine inhibit the denaturation of native IgG, or prevent the synthesis of abnormal immunoglobulins cannot as yet be proved, but either mechanism will bring about a fall in the number of exposed antigenic sites on the IgG molecule, and thus reduce the stimulus for IgM rheumatoid factor production.

There are 2 reasons for expecting the disappearance of IgM rheumatoid factor to be a slow process; first, antibodies do not disappear immediately the stimulus for their production has been removed and secondly, the proposed reaction can only take place in newly forming immunoglobulins. This hypothesis not only accounts for the observed falls in DAT, and total and cryoprecipitable IgM, and the rise in synovial $\mathrm{CH} 50$, but also for the known dela $\overline{\frac{8}{3}}$ in the clinical response following the initiation of treatment.

The authors gratefully acknowledge the experi technical assistance of Mrs Michelle Evans, and the financial support of the Welsh Office and The Arth $\frac{\bar{\sigma}}{\bar{c}}$ ritis and Rheumatism Council.

\section{References}

Chwalinska-Sadowska, H., and Baum, J. (1976). The effeca of D-penicillamine on polymorphonuclear leucocyte function. Journal of Clinical Investigation, 58, 871-879. $\vec{\omega}$

Deutch, H. F., and Morton, J. I. (1957). Dissociation of human serum macroglobulins. Science, 125, p. 600 .

Empire Rheumatism Council Multicentre Trial. (1960). Golæ therapy in rheumatoid arthritis. (Preliminary report $\mathcal{L}^{\circ}$ Annals of the Rheumatic Diseases, 19, 95-117.

Empire Rheumatism Council Multicentre Trial. (1961). Gold therapy in rheumatoid arthritis. (Final report.) Annals the Rheumatic Diseases, 20, 315-333.

Evans, P. H. (1975). Serum sulphydryl levels in rheumatoi 웡 patients treated with alclofenac. Current Medical Researct and Opinion, 3, 268-273.

Evans, P. H. (1977). Serum sulphydryl changes in rheumatoi coalworker's pneumoconiosis patients treated with DP penicillamine. Proceedings of the Royal Society of Medicing 70, Suppl. 3, 95-97.

Findlay, G. M., Mackenzie, R. D., and MacCallum, $F_{\Omega} \mathrm{O}^{-}$ (1940). Chemotherapeutic experiments on pleuropneugios nia-like organisms in rodents. British Journal of Experio mental Pathology, 21, 13-22.

Gaarder, and Natvig, J. B. (1974). The reaction rheumatoid anti-Gm antibodies with native and aggre

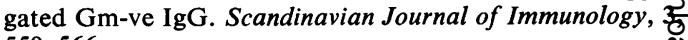
559-566.

Gerber, D. A. (1974). Copper catalysed thermal aggregation of human gamma-globulin. Arthritis and Rheumatism, 17 85-91.

Gerber, D. A. (1975). Sulphydryl dependent thermal aggre gation of human gamma-globulin. Arthritis and Rhe umatism, 18, 59-66.

Golding, J. R., Wilson, J. V., and Day, A. T. (1970). Observation on the treatment of rheumatoid disease with penicillamine. Postgraduate Medical Journal, 46, 599-60.

Hannestad, K. (1967). Presence of aggregated gamma globulin in certain rheumatoid synovial effusions. Clinic $\overrightarrow{\mathbf{\theta}}$ and Experimental Immunology, 2, 511-529.

Hedburg, H. (1967). Studies of synovial fluid in arthritis Acta Medica Scandinavica, Suppl. 479, 47-62.

Huskisson, E. C., Dudley Hart, F., and Lacey, B. W. (19719 Synovial fluid Waaler-Rose and latex tests. Annals of the Rheumatic Diseases, 30, 67-72.

Huskisson, E. C., Wojtulewski, J., Scott, J., Balme, HE Burry, H. C., and Grahame, R. (1977). Comparative study of gold and D-penicillamine in the treatment of rheumator arthritis. XIV International Congress of Rheumatologn San Francisco. (Abstract no. 269.)

Jaffe, I. A. (1962). Intra-articular dissociation of rheumatofe factor. Journal of Laboratory and Clinical Medicine, 贯 409-421.

Jaffe, I. A. (1963). Comparison of the effect of plasmapheresting and penicillamine on the level of circulating rheumatod factor. Annals of the Rheumatic Diseases, 22, 71-76.

Jaffe, I. A. (1965). The effect of penicillamine on the labora tory parameters in rheumatoid arthritis. Arthritis af Rheumatism, 8, 1064-1079. 
Jaffe, I. A. (1977). Actions of gold and penicillamine. In Rheumatoid Arthritis, Cellular Pathology and Pharmacology, pp. 131-142, edited by J. L. Gordon \& B. L. Hazleman. North-Holland; Oxford.

Jellum, E., and Munthe, E. (1977). Is the mechanism of action during treatment of rheumatoid arthritis with penicillamine and gold the same? In Perspectives in Inflammation, pp. 575-581, edited by D. A. Willoughby, J. P. Giroud \& G. P. Velo. MTP Press: London.

Jessop, J. D., Vernon-Roberts, B., and Harris, J. (1973). Effects of gold salts and prednisone on inflammatory cells. 1: Phagocytic activity of macrophages and polymorphs in inflammatory exudates studied in a 'skin-window' technique in rheumatoid and control patients. Annals of the Rheumatic Diseases, 32, 294-300.

Jessop, J. D., and Currey, H. L. F. (1968). Influence of gold salts on adjuvant arthritis in the rat. Annals of the Rheumatic Diseases, 27, 577-581.

Liyanage, S. P., and Currey, H. L. F. (1972). Failure of oral D-penicillamine to modify adjuvant arthritis or immune response in the rat. Annals of the Rheumatic Diseases, 31, 521.

Marcus, R. L., and Townes, A. S. (1971). The occurrence of cryoproteins in synovial fluid; the association of a complement fixing activity in rheumatoid synovial fluid with gold precipitable protein. Journal of Clinical Investigation, 50, 282-283.

Mayer, M. M. (1961). Complement and complement fixation. In Experimental Immunochemistry, 2nd ed., edited by F. A. Kabat and M. M. Meyer, Thomas: Springfield, Ill. Mellbye, O. J., and Munthe, E. (1977). Effect of penicillamine on complement in vivo and in vitro. Annals of the Rheumatic Diseases, 36, 453-458.

Merryman, P., Jaffe, A., and Ehrenfeld, E. (1974). Effect of D-penicillamine on polio virus replication in Hela cells. Journal of Virology, 13, 881-887.

Mohammed, I., Barraclough, D., Holborow, E. J., and Ansell, B. M. (1976). Effect of penicillamine on circulating complexes in rheumatoid arthritis. Annals of the Rheumatic Diseases, 35, 458-462.

Mowat, A. (1977). Neutrophil chemotaxis in rheumatoid arthritis: drug effects. In Rheumatoid Arthritis, Cellular Patho!ogy and Pharmacology, pp. 51-56, edited by J. L. Gordon and B. L. Hazleman, North-Holland: Oxford.
Multicentre Trial Group (1973). Controlled trial of Dpenicillamine in severe rheumatoid arthritis. Lancet, 1, 275-280.

Pekin, T. J., and Zvaifler, N. J. (1964). Haemolytic complement in synovial fluid. Journal of Clinical Investigation, 43, 1372-1382.

Persellin, R. H., Hess, E. V., and Ziff, M. (1967). Effect of a gold salt on the immune response. Arthritis and Rheumatism, 10, 99-106.

Persellin, R. H. and Ziff, M. (1966). The effect of gold salt on lysosoma! enzymes of the periotoneal macrophage. Arthritis and Rheumatism, 9, 57-65.

Preston, E. S., Block, W. D., and Freyberg, R. H. (1942). Chemotherapy of chronic progressive arthritis in mice. 1 : role of sulfur in gold containing compounds. Proceedings of the Society of Experimental Biology and Medicine, 50, 253-256.

Ropes, M. W., Bennet, G. A., Cobb, S., Jacox, J., and Jessar, R. H. (1959). Diagnostic criteria for rheumatoid arthritis. Annals of the Rheumatic Diseases, 18, 49-53.

Rose, H. M., Ragan, C., Pearce, E. and Lipman, M. O. (1948). Differential agglutination of normal and sensitised sheep erythrocytes by sera of patients with rheumatoid arthritis. Proceedings of the Society of Experimental Biology and Medicine, 68, 1-6.

Schultz, D. R., Volanakis, J. E., Arnold, P. I., Gottlieb, N. L., Sakai, K., and Stroud, R. M. (1974). Inactivation of Cl in rheumatoid synovial fluid, purified $\mathrm{Cl}$ and $\mathrm{Cl}$ Esterase, by gold compounds. Clinical Experimental Immunology, 17, 395-406.

Tesar, J. T., and Schmid, F. R. (1970). Conversion of soluble immune complexes into complement-fixing aggregates by IgM rheumatoid factor. Journal of Immunology, 105, 1206-1214.

Winchester, R. J., Agnello, V., and Kunkel, J. G. (1970). Gamma globulin complexes in synovial fluid of patients with rheumatoid arthritis. Clinical and Experimental Immunology, 6, 689-706.

Wollheim, F. A., Jeppsson, J. O., and Laurell, C. B. (1977). Plasma Cystine, urinary penicillamine cystein and plasma alfa $_{1}$ antitrypsin complexes during penicillamine treatment. In 1st WHO/ILAR Advanced Course on Rheumatoid Arthritis and Allied Diseases. (Abstract.) 